\title{
The Rise and Fall of Anticoagulation with Bivalirudin During Percutaneous Coronary Interventions: A Review Article
}

\author{
Constantinos Andreou · Christos Maniotis · Michael Koutouzis
}

Received: November 28, 2016 / Published online: January 19, 2017

(C) The Author(s) 2017. This article is published with open access at Springerlink.com

\section{ABSTRACT}

Bivalirudin is a direct thrombin inhibitor used during percutaneous coronary intervention (PCI). Treatment with bivalirudin compared to heparin plus glycoprotein IIb/IIIa inhibitors (GPI) reduced bleeding complications, but resulted in higher rates of ischemic events, including acute stent thrombosis in ST segment elevation myocardial infarction (STEMI) patients. Thus, it may be considered a reasonable alternative antithrombotic agent in patients at high risk of bleeding undergoing PCI. However its superiority over heparin alone is questioned particularly in the era of novel antiplatelet agents and transradial PCI.

Keywords: ACS; Bivalirudin; PCI

Enhanced content To view enhanced content for this article go to http://www.medengine.com/Redeem/1D77 F0603E8B4DEF.

C. Andreou

Cardiology Department, Leiden University Medical

Center, Leiden, The Netherlands

C. Maniotis · M. Koutouzis $(\square)$

2nd Cardiology Department, Hellenic Red Cross

General Hospital, Athens, Greece

e-mail: koutouzismike@yahoo.gr

\section{INTRODUCTION}

Thrombosis is the main pathophysiologic mechanism of acute coronary syndromes (ACS) and thrombin plays a pivotal role in the coagulation cascade and thrombus formation in this clinical setting [1]. Bivalirudin is a direct thrombin inhibitor that provides potent and effective control of thrombin activity and has been proved a useful and effective therapeutic agent in a broad spectrum of patients with coronary syndromes undergoing percutaneous coronary intervention (PCI) $[2,3]$.

Bivalirudin is an oligopeptide analogue of the naturally produced hirudin that binds reversibly to both the active site and exosite I of thrombin [4]. Bivalirudin, contrary to heparin, inhibits effectively both the free fibrin-bound thrombin, is not inactivated by platelet factor 4 , does not require antithrombin for its activity, does not bind to proteins and matrices other than thrombin, has low immunogenic potential, and does not cause heparin-induced thrombocytopenia [4, 5]. Despite these theoretical advantages of bivalirudin, in clinical practice its superiority over heparin is doubted. Our review aims to collect and interpret all relevant data regarding bivalirudin's efficacy in PCI and clarify if it could be considered as a reasonable antithrombotic option in different clinical settings during PCI.

This article is based on previously conducted studies and does not involve any new studies of 
human or animal subjects performed by any of the authors.

\section{BIVALIRUDIN IN PCI}

\section{Bivalirudin and Low to Moderate Risk Patients Undergoing PCI}

Unfractionated heparin (UFH) has been the main antithrombotic therapy during PCI. The additional administration of glycoprotein IIb/ IIIa inhibitors (GPI) during PCI is helpful to prevent thrombotic complications in patients with ACS, but not in low risk patients pretreated with thienopyridines [6]. Therapy with GPI is not used universally because, as potent platelet inhibitors, they carry an increased bleeding risk. Bivalirudin, a direct thrombin inhibitor with predictable biophysical availability, is an alternative antithrombotic agent which can be used instead of heparin.

The establishment of bivalirudin as an antithrombotic agent was based primarily on the results of BAT (Bivalirudin Angioplasty Trial). Patients with unstable or postinfarction angina were randomly assigned to receive either bivalirudin or heparin immediately before angioplasty. Bivalirudin therapy compared with heparin was associated with a $22 \%$ reduction of ischemic and $62 \%$ reduction of bleeding complications, respectively [7]. The exclusive use of balloon-only angioplasty, without stent implantation, the absence of pretreatment with thienopyridines, the high dose of heparin administration (bolus dose of 175 units/kg and infusion at a rate of 15 units/ $\mathrm{kg}$ for $18-24 \mathrm{~h}$ ), and the outdated regimen of bivalirudin (bolus dose of $1 \mathrm{mg} / \mathrm{kg}$ and infusion at a rate of $2.5 \mathrm{mg} / \mathrm{kg} / \mathrm{h}$ for $4 \mathrm{~h}$ and $0.2 \mathrm{mg} / \mathrm{kg} / \mathrm{h}$ for $14-20 \mathrm{~h}$ ) make the results of this study difficult to compare to current interventional practice. The feasibility of bivalirudin during PCI in the contemporary era of elective coronary stenting and dual antiplatelet therapy was evaluated by CACHET (Comparison of Abciximab Complications with Hirulog for Ischemic Events Trial) and REPLACE-1 (Randomized Evaluation of PCI Linking Angiomax to Reduced Clinical
Events-1) trials. Bivalirudin with provisional or planned GPI compared to heparin plus GPI resulted in lower rates of major bleeding and similar rates of ischemic events according to the CACHET [8] trial. In the REPLACE-1 trial the ischemic and hemorrhagic end points were approximately 20\% lower among patients randomized to bivalirudin compared to those randomized to heparin. However, the beneficial effects of bivalirudin on bleeding were observed only in the subgroup of patients who did not receive GPI [9]. These observations were in part the rationale for use of provisional rather than planned GPI in the bivalirudin arm of the following REPLACE-2 trial.

The REPLACE-2 (Randomized Evaluation of PCI Linking Angiomax to Reduced Clinical Events-2) trial compared bivalirudin with the combination of heparin plus GPI. Patients with positive stress test, unstable and stable angina were enrolled in this trial. Patients were randomized to receive either bivalirudin with provisional GPI or heparin plus planned GPI (abciximab or eptifibatide). The composite primary end point occurred in $9.2 \%$ of patients participating in the bivalirudin group and $10 \%$ of patients who received heparin and GPI $(p=0.32)$ (Table 1). Regarding the ischemic events, bivalirudin with provisional GPI was proved not inferior to GPI plus heparin, despite the not statistically significant trend toward a higher incidence of non-Q wave MI observed in the bivalirudin group. A remarkable result of REPLACE- 2 was the $41 \%$ relative reduction of major in-hospital bleeding in the bivalirudin arm $(2.4 \%$ vs. $4.1 \%, p<0.001)$ [10] which resulted in a trend of better survival rates after 6 months and 1-year follow-up [11].

ISAR-REACT 3 (Intracoronary Stenting and Antithrombotic Regimen: Rapid Early Action for Coronary Treatment 3), a double-blind trial, was designed to evaluate bivalirudin as monotherapy, exclusively in patients with stable or unstable angina undergoing PCI and compared it with UFH alone. For that reason GPI were administered in only $0.2 \%$ of patients in each group. Concerning the quadruple primary end point, bivalirudin did not provide any net clinical benefit, or any harm, compared with heparin at 30-day follow-up (Table 1). The 
Table 1 Summary of key clinical trials examining the role of bivalirudin in coronary artery diseases

\begin{tabular}{|c|c|c|c|c|}
\hline Year & Trial & Population & Primary end point & Result \\
\hline 2003 & REPLACE-2 & $\begin{array}{l}\text { Patients without } \\
\text { acute MI }\end{array}$ & $\begin{array}{l}\text { Composite of death, MI, urgent repeat } \\
\text { revascularization within } 30 \text { days of } \\
\text { randomization or in-hospital major } \\
\text { bleeding }\end{array}$ & $\begin{array}{l}9.2 \% \text { bivalirudin vs. } 10 \% \\
\text { heparin plus GPI, } \\
p=0.32\end{array}$ \\
\hline 2006 & ACUITY & ACS patients & $\begin{array}{l}\text { 1st: } 30 \text {-day composite ischemic end point } \\
\text { (death, MI, unplanned revascularization } \\
\text { for ischemia) } \\
\text { 2nd: } 30 \text {-day major bleeding } \\
\text { 3rd: } 30 \text {-day net clinical outcome } \\
\text { (composite of ischemia or major } \\
\text { bleeding) }\end{array}$ & $\begin{array}{l}\text { (a) } 7.7 \% \text { bivalirudin plus } \\
\text { GPI vs. } 7.3 \% \text { heparin plus } \\
\text { GPI, } p=0.39 \\
\text { (b) } 7.8 \% \text { bivalirudin alone } \\
\text { vs. } 7.3 \% \text { heparin plus GPI, } \\
p=0.3 \\
\text { (a) } 5.3 \% \text { bivalirudin plus } \\
\text { GPI vs. } 5.7 \% \text { heparin plus } \\
\text { GPI, } p=0.38 \\
\text { (b) } 3.0 \% \text { bivalirudin alone } \\
\text { vs. } 5.7 \% \text { heparin plus GPI, } \\
p<0.001 \\
\text { (a) } 11.8 \% \text { bivalirudin plus } \\
\text { GPI vs. } 11.7 \% \text { heparin plus } \\
\text { GPI, } p=0.93 \\
\text { (b) } 10.1 \% \text { for bivalirudin } \\
\text { alone vs. } 11.7 \% \text { for heparin } \\
\text { plus GPI, } p=0.02\end{array}$ \\
\hline 2008 & HORIZONS-AMI & STEMI patients & $\begin{array}{l}\text { 1st: } 30 \text {-day major bleeding } \\
\text { 2nd: } 30 \text {-day combined adverse clinical } \\
\text { events (death, reinfarction, target vessel } \\
\text { revascularization for ischemia, stroke, and } \\
\text { major bleeding) }\end{array}$ & $\begin{array}{l}\text { 4.9\% bivalirudin vs. } 8.3 \% \\
\text { heparin plus GPI, } \\
p<0.001 \\
9.2 \% \text { for bivalirudin vs. } \\
12.1 \% \text { for heparin plus } \\
\text { GPI, } p=0.005\end{array}$ \\
\hline 2008 & ISAR-REACT 3 & $\begin{array}{l}\text { Stable or } \\
\text { unstable angina }\end{array}$ & $\begin{array}{l}\text { Composite of death, MI, urgent target } \\
\text { vessel revascularization for ischemia } \\
\text { within } 30 \text { days for randomization or } \\
\text { major bleeding during hospitalization }\end{array}$ & $\begin{array}{l}8.3 \% \text { bivalirudin vs. } 8.7 \% \\
\text { heparin, } p=0.57\end{array}$ \\
\hline 2011 & ISAR-REACT 4 & $\begin{array}{l}\text { NSTEMI } \\
\text { patients }\end{array}$ & $\begin{array}{l}\text { Composite end point of death, large } \\
\text { recurrent MI, urgent target vessel } \\
\text { revascularization or major bleeding } \\
\text { within } 30 \text { days from randomization }\end{array}$ & $\begin{array}{l}11 \% \text { bivalirudin vs. } 10.9 \% \\
\text { abciximab plus heparin, } \\
p=0.94\end{array}$ \\
\hline 2013 & EUROMAX & $\begin{array}{l}\text { STEMI patients } \\
\text { transferred for } \\
\text { PPCI }\end{array}$ & $\begin{array}{l}\text { Composite of death or major bleeding at } \\
30 \text { days }\end{array}$ & $\begin{array}{l}5.1 \% \text { bivalirudin vs. } 8.5 \% \\
\text { heparin or enoxaparin, } \\
p=0.001\end{array}$ \\
\hline
\end{tabular}


Table 1 continued

\begin{tabular}{|c|c|c|c|c|}
\hline Year & Trial & Population & Primary end point & Result \\
\hline 2014 & HEAT-PPCI & STEMI patients & $\begin{array}{l}\text { Composite of all-cause mortality, } \\
\text { cerebrovascular accident, reinfarction or } \\
\text { unplanned target lesion revascularization } \\
\text { at } 28 \text { days }\end{array}$ & $\begin{array}{l}8.7 \% \text { for bivalirudin vs. } 5.7 \% \\
\text { for heparin, } p=0.01\end{array}$ \\
\hline 2014 & NAPLES III & $\begin{array}{l}\text { Elective PCI in } \\
\text { high risk } \\
\text { bleeding } \\
\text { patients }\end{array}$ & In-hospital major bleeding & $\begin{array}{l}3.3 \% \text { bivalirudin vs. } 2.6 \% \\
\text { UFH, } p=0.54\end{array}$ \\
\hline 2014 & BRIGHT & MI patients & $\begin{array}{l}\text { A composite of death from any cause, } \\
\text { reinfarction, ischemia-driven target vessel } \\
\text { revascularization, stroke, or any bleeding } \\
\text { at } 30 \text { days }\end{array}$ & $\begin{array}{l}8.8 \% \text { bivalirudin vs. } 13.2 \% \\
\text { heparin, vs. } 17 \% \text { for } \\
\text { heparin plus tirofiban, } \\
p<0.001\end{array}$ \\
\hline 2015 & MATRIX & $\begin{array}{l}\text { STEMI and } \\
\text { NSTEMI } \\
\text { patients }\end{array}$ & $\begin{array}{l}\text { Whether bivalirudin with bailout GP IIb/ } \\
\text { IIIa inhibitor (GPI) use was superior to } \\
\text { UFH with planned or bailout GPI use in } \\
\text { reducing MACE }\end{array}$ & $\begin{array}{l}\text { STEMI patients: } 5.9 \% \\
\text { bivalirudin vs. } 6.5 \% \\
\text { heparin, } p=0.43 \\
\text { NSTEMI patients: } 15.9 \% \\
\text { bivalirudin vs. } 16.4 \% \\
\text { heparin, } p=0.74\end{array}$ \\
\hline
\end{tabular}

beneficial effects of bivalirudin on major bleeding rate were verified in this trial. On the other hand a trend toward a higher incidence of MI in the bivalirudin arm has blunted any clinical benefit resulting from the lower risk of bleeding [12]. At 1 year neither the composite end point of death, MI, and target vessel revascularization nor its individual components separately differed in the trial's troponin-negative patients, independently of the antithrombotic regimen they received. Furthermore the stent thrombosis events were identical for both bivalirudin and heparin treatment groups [13].

The role of bivalirudin in patients undergoing elective PCI was further investigated by smaller trials. The ARNO (Antithrombotic Regiments and Outcome) trial, a double randomized trial, compared bivalirudin and heparin plus protamine in both troponin-positive and negative-patients undergoing PCI. Although heparin was neutralized by protamine at the end of intervention, in-hospital major bleeding rate was fourfold less in the bivalirudin arm, supporting that bivalirudin's safe profile regarding the bleeding risk is not only due to its short half time. Also bivalirudin unexpectedly reduced the ischemic events, despite the more frequent use of abciximab in the heparin group. The 30-day secondary efficacy end point of death, MI, and unplanned revascularization was greater in the heparin arm; this is a unique observation that has not been previously reported. With regard to the fewer thrombotic complications and the lower rates of major bleeding, bivalirudin was associated with better 1- and 6-month net clinical outcome [14].

The bivalirudin's beneficial effects on bleeding were questioned by the NAPLES III trial (Novel Approaches in Preventing or Limiting Event III). Bivalirudin compared to heparin failed to reduce in-hospital bleeding in high risk bleeding patients undergoing elective PCI through the femoral approach. The reduced 
heparin dose used in this trial and the absence of concomitant GPI administration in the UFH arm may explain the similar rates of bleeding between the two groups. Regarding ischemic events including MI, stent thrombosis, and revascularization at 30 days and 1 year, no differences emerged between the two antithrombotic strategies. The trial result is interesting and raises doubt on the positive impact of bivalirudin on bleeding and thus may influence clinical practice [15].

The different and sometimes controversial results of the cited studies can be difficult to explain, compare, and interpret because of the different patient populations and treatment algorithms. In current European guidelines for revascularization, in stable coronary disease patients undergoing PCI, bivalirudin has a Class I recommendation with level of evidence $\mathrm{C}$ in case of heparin-induced thrombopenia and Class IIa recommendation with level of evidence $\mathrm{A}$ in high bleeding risk patients undergoing PCI [16].

\section{Bivalirudin and High Risk Patients Undergoing PCI}

Bivalirudin has also been evaluated in patients with ACS. The PROTECT-TIMI 30 trial randomized ACS patients undergoing PCI and examined whether eptifibatide plus UFH or enoxaparin had better coronary flow reserve after PCI compared to bivalirudin. Although bivalirudin monotherapy was associated with higher coronary flow reserve, treatment with eptifibatide resulted in improved myocardial perfusion and decreased duration of ischemia after PCI. Minor but not major bleeding and transfusion rates were lower among patients treated with bivalirudin, supporting again its beneficial effects regarding bleeding [17]. The ACUITY (Acute Catheterization and Urgent Intervention Triage Strategy) trial was the first large-scale, prospective, randomized trial comparing bivalirudin monotherapy with provisional use of GPI, bivalirudin plus GPI, and heparin (either UFH or enoxaparin) plus GPI in the clinical setting of ACS. Patients with either myocardial infarction without persistent
ST segment elevation (NSTEMI) or unstable angina were enrolled in this trial. The basic finding of this trial was that bivalirudin monotherapy with the provisional use of GPI compared with heparin plus GPI reduced significantly the rate of major bleeding, without a simultaneous increase in the ischemic events even among the highest risk patients enrolled, thus resulting in a reduction of the net clinical outcome (Table 1). Bivalirudin monotherapy also decreased the incidence of bleeding from any cause, minor bleeding according to TIMI scale, and blood transfusions. Interestingly there was an increase of the ischemic events in the subgroup of patients who participated in the bivalirudin monotherapy group and did not receive a thienopyridine before angioplasty, compared with patients treated with heparin plus GPI. In contrast, pretreatment with a thienopyridine resulted in similar incidence of ischemic events in both groups. Therefore the administration of thienopyridines before angioplasty is desirable in order to optimize the outcomes of bivalirudin as a monotherapy, an approach that is consistent with current guidelines [18]. The comparison of bivalirudin plus GPI and heparin plus GPI did not reveal a winner. Both antithrombotic therapies resulted in similar 30-day rates of the composite ischemia end point, major bleeding, and the net clinical outcome end point [2].

Patients with ACS with non-persistent ST segment elevation represent a higher risk patient group [19]. The ISAR-REACT 4 (Intracoronary Stenting and Atithrombotic Regimen: Rapid Early Action for Coronary Treatment 4) trial was a randomized trial evaluating non-inferiority of bivalirudin versus heparin plus abciximab in NSTEMI patients who needed an early invasive revascularization. The antithrombotic approach with the combination of abciximab plus heparin, compared to bivalirudin, failed to reduce the rate of primary end point (Table 1). Conversely, it increased the risk of bleeding without providing any benefit in protection against ischemic events. Therefore, bivalirudin was associated with a lower incidence of major and minor bleeding and showed an 
anti-ischemic protection similar to that offered by abciximab and heparin without any increased risk of stent thrombosis or death [20]. The beneficial effects of bivalirudin on bleeding did not translate to a better 1-year survival. Nevertheless, bivalirudin was not inferior to heparin plus abciximab and provided comparable long-term clinical outcomes including death, MI, and target vessel revascularization $[20,21]$.

Bivalirudin was also evaluated in patients with NSTEMI receiving fondaparinux. SWITCH III is a randomized, multicenter study which aimed to evaluate the safety of bivalirudin versus UFH in patients with NSTEMI, initially treated with fondaparinux and urgent PCI. The investigators did not reveal any significant differences in hemorrhagic or ischemic end points between the two groups. Bivalirudin was not inferior to UFH regarding bleeding, death, MI, acute revascularization, stent thrombosis, and reinfarction [22]. Furthermore, an observational retrospective analysis showed that treatment with bivalirudin plus provisional GPI during elective or urgent PCI in patients who initially received fondaparinux resulted in statistically lower rates of clinically apparent bleeding or bleeding requiring transfusions and a trend to a lower mortality compared with UFH plus provisional GPI [23]. In the current European Society of Cardiology (ESC) guidelines for NSTEMI, the use of bivalirudin in ACS patients pretreated with fondaparinux is not clarified because, at the time of publication, the only anticoagulant evaluated with fondaparinux during PCI was UFH [18].

\section{Is Bivalirudin Monotherapy Superior to Heparin Alone in the Treatment of NSTEMI Patients Undergoing PCI?}

Previously a Swedish group extracted and analyzed retrospective data from the Swedish Coronary Angiography and Angioplasty Registry (SCAAR) and compared the 30-day mortality between treatment with bivalirudin alone and heparin (UFH or LMWH) in patients with NSTEMI who underwent PCI. Of note, contrary to the previously mentioned studies, patients who received GPI were excluded. A total of 41,534 consecutive patients who were treated with either heparin alone or bivalirudin between 2005 and 2011 were included in this study [24]. The results were quite impressive and unexpected. Treatment with heparin was associated with a significant decrease in 30-day mortality compared to bivalirudin, a finding that should be verified by a randomized trial. The current ESC guidelines for NSTEMI gave a class I, level of evidence A, recommendation for bivalirudin $(0.75 \mathrm{mg} / \mathrm{kg}$ iv bolus followed by $1.75 \mathrm{mg} / \mathrm{kg} / \mathrm{h}$ for up to $4 \mathrm{~h}$ after the procedure) as an alternative to UFH plus GPI receptor inhibitors [18].

\section{Bivalirudin and Patients with ST Segment Elevation Myocardial Infarction Undergoing PCI}

Patients with STEMI represent a population requiring prompt reperfusion with primary PCI (PPCI) being the best option [25]. The HORIZONS-AMI (Harmonizing Outcomes with Revascularization and Stents in Acute Myocardial Infarction) study was the first prospective, randomized multicenter trial that aimed to compare bivalirudin to heparin plus a GPI (abciximab or eptifibatide) in STEMI patients who were treated with PPCI. Approximately $7.2 \%$ of patients assigned to bivalirudin received GPI because of either no reflow or high thrombus burden after PPCI [3]. As primary end points were defined, the combined clinical events were determined as the combination of major bleeding and major adverse cardiovascular events (MACE; death, reinfarction, target vessel revascularization for ischemia, and stroke) and major bleeding not related to coronary artery bypass graft (CABG) at 30 days. Patients who were assigned to bivalirudin had a significant reduction of net adverse clinical events $(9.2 \%$ vs. $12.1 \%$, $p=0.005)$ compared to heparin plus GPI (Table 1) mainly owing to the lower rates of major bleeding $(4.9 \%$ vs. $8.3 \% ; p<0.001)$. Importantly, both rates of 30-day mortality from cardiac causes and all-cause mortality 
were significantly lower in the bivalirudin arm (1.8\% vs. $2.9 \%, p=0.03$ and $2.1 \%$ vs. $3.1 \%$, $p=0.047$, respectively). Rates of reinfarction, target vessel revascularization, and stroke did not differ significantly between the two anticoagulant options. Bivalirudin treatment resulted in lower rates of blood transfusions and thrombocytopenia. However there was a significant $1.0 \%$ increase of stent thrombosis during the first $24 \mathrm{~h}$ after PCI among patients treated with bivalirudin [3].

The superiority of bivalirudin over the combination of heparin and GPI was substantially confirmed after 1-year follow-up. Noteworthy, the differences in survival between the two groups were widened between 30 days and 1 year, indicating that the beneficial effects of bivalirudin do not only relate to the periprocedural period but also translates to long-term positive impact on mortality. Additionally, at the end of the 1-year follow-up, the rates of stent thrombosis were similar between the two anticoagulation treatments, indicating that the initial increase of stent thrombosis in the bivalirudin group was counterbalanced by a subsequent decrease of stent thrombosis between $24 \mathrm{~h}$ and 1 year, compared to the control group [26]. After a 3-year follow-up, treatment with bivalirudin was independently associated with a 43\% reduction in 3-year cardiac mortality, even after a multivariate analysis taking into account major bleeding, thrombocytopenia, and reinfarction [27].

Although HORIZONS-AMI remains the largest study that established the utility of bivalirudin in STEMI patients undergoing PPCI, a careful reading of its design reveals an important limitation [28]. More than $65 \%$ of the patients assigned to the bivalirudin group had received a bolus of UFH before randomization. Therefore the bivalirudin was not actually compared as a monotherapy to heparin plus GPI. Patients treated with bivalirudin who received UFH before randomization had a more favorable prognosis compared to those who did not $(4.6 \%$ vs. $7.2 \%$ for the primary end point of the study). This fact raised same questions about the beneficial effects of UFH in patients treated with bivalirudin during PPCI. A study from Sweden aimed to evaluate retrospectively the effect of the addition of bolus UFH in administration to bivalirudin in patients with STEMI undergoing PPCI. Bivalirudin monotherapy during PCI was compared with periprocedural bivalirudin plus UFH. The main finding was that the additional administration of bolus UFH in STEMI patients receiving bivalirudin during PCI resulted in lower rates of death or definite target lesion thrombosis. A probable interpretation is that bivalirudin alone cannot provide effective anticoagulation in this high thrombotic clinical setting, because of its short half time. Considering that the pretreatment with UFH has been proved not to increase bleeding risk in STEMI patients receiving bivalirudin, an extra bolus administration of UFH in this group of patients should be reasonable [29].

Many changes occurred since the HORIZONS-AMI trial was conducted. Novel $\mathrm{P}_{2} \mathrm{Y}_{12}$ inhibitors, such as ticagrelor and prasugrel, and the radial artery access have increasingly been adopted. The EUROMAX (European Ambulance Acute Syndrome Angiography) trial was an international, randomized trial that aimed to assess whether bivalirudin administered during patient's transport for PPCI was superior to heparin plus optional GPI in the contemporary era of radial artery access and new antiplatelet agents. Among patients assigned to the bivalirudin group, only a small proportion received either heparin $(2.2 \%)$ or GPI $(11.5 \%)$. On the other hand, most of the patients (69.1\%) participating in the heparin group had received GPI. The trial's primary end point occurred in $5.1 \%$ of the patients received bivalirudin and $8.5 \%$ of the patients treated with heparin plus optional use of GPI $(p=0.001) \quad$ (Table 1). Prehospital administration of bivalirudin was associated with reduction of both major and minor bleeding as well as transfusions, compared with the heparin group, regardless of the choice of arterial access and $\mathrm{P}_{2} \mathrm{Y}_{12}$ inhibitors. Despite the HORIZONS-AMI trial, the beneficial effects of bivalirudin on bleeding were not translated to a decrease in mortality. The risk of acute stent thrombosis within $24 \mathrm{~h}$ was greater in the bivalirudin group compared 
with the control group. The prolonged, reduced-dose infusion of bivalirudin and the use of new $\mathrm{P}_{2} \mathrm{Y}_{12}$ with more rapid and potent action failed to reduce this risk. The increased rates of stent thrombosis resulted in a non-significant increased incidence of reinfarction and ischemia-driven revascularization in the bivalirudin group. In conclusion, the EUROMAX trial suggested bivalirudin as an anticoagulant treatment in STEMI patients, with lower rates of bleeding, but higher rates of acute stent thrombosis [30].

\section{Is Bivalirudin Monotherapy Superior to Heparin Alone in the Treatment of STEMI Patients Undergoing PCI?}

The single-center HEAT-PPCI (How Effective are Antithrombotic Therapies in Primary Percutaneous Coronary Intervention) trial compared bivalirudin and heparin in patients stented for STEMI. The HEAT-PPCI trial revealed heparin as the clear winner, as patients treated with heparin were less likely to have either reinfarction or stent thrombosis compared to those in the bivalirudin arm, without a concomitant increase of bleeding events (Table 1). This was the first trial that demonstrated bivalirudin's inferiority compared to heparin [31]. However the BRIGHT (Bivalirudin Monotherapy vs. Heparin Monotherapy vs. Heparin Plus Tirofiban AMI Patients Undergoing Coronary Intervention) trial, a randomized multicenter trial, showed that bivalirudin in NSTEMI and STEMI patients resulted in lower rates of the combined primary end point of death, reinfarction, ischemia-driven vessel revascularization, stroke, or bleeding at 30 days (Table 1) and 1 year compared to either UFH alone or UFH plus tirofiban. Bleeding events were significantly reduced by the bivalirudin strategy compared to heparin without any concomitant increase in ischemic events, including stent thrombosis. Possibly the higher dose in the heparin monotherapy arm $(100 \mathrm{U} / \mathrm{kg}$, greater than was used in HEAT-PPCI) may explain the increased bleeding events in the heparin monotherapy group. Also the prolonged high dose $(1.75 \mathrm{mg} / \mathrm{kg} / \mathrm{h})$ bivalirudin infusion lasting $3-4 \mathrm{~h}$ after PCI potentially could relate to the lack of stent thrombosis in the bivalirudin arm [32]. The MATRIX Antithrombin study, part of the MATRIX program was a randomized comparison of bivalirudin with UFH in acute coronary syndrome patients with or without ST segment elevation. GPI use was restricted in angiographic complications in the bivalirudin arm and it was left to the discretion of the investigator in the UFH arm. The MACE end point, a composite end point that included death, MI, or stroke, was not statistically different between the two treatment regimens independently of the presence or not of ST segment elevation. However, bivalirudin compared to heparin was associated with lower rates of all-cause and cardiovascular mortality at 30 days both in patients with $(0.68,95 \%$ CI $0.46-1.01, p=0.053$ and 0.67 , $95 \%$ CI $0.45-1.00, p=0.048)$ and without $(0.77$, $95 \%$ CI $0.41-1.46, p=0.43$ and $0.76,95 \%$ CI $0.40-1.47, p=0.42)$ ST segment elevation. The rates of stent thrombosis and myocardial infarction at 30 days were similar between the two groups in patients with and without ST segment elevation. Regarding the net clinical event end point-a composite end point that included death, MI, stroke, and major bleeding-there was no significant difference between the two antithrombin regimens. However, bleeding rates were significantly reduced with bivalirudin. Bivalirudin treatment resulted in lower rates of BARC (Bleeding Academic Research Consortium) 3 and 5 both in STEMI patients $(0.60,95 \%$ CI $0.39-0.92 ; p=0.019)$ and in patients without ST segment elevation $(0.47,0.26-0.85 ; p=0.011)$ [33].

The results of the trials that compared bivalirudin and heparin monotherapies are controversial. Thus, a meta-analysis aimed to clarify the superiority or not of bivalirudin compared to heparin, in the broad spectrum of patients undergoing PCI. Pooling and analyzing data from all relevant randomized trials, this study showed that treatment with bivalirudin resulted in increased rates of MACE, mainly due to the increased incidence of $\mathrm{MI}$ and 
ischemia-driven revascularization. On the other hand bivalirudin reduced the risk of bleeding events. However the magnitude of this reduction was influenced by the concomitant use of GPI. The greater benefit regarding bleeding achieved with the bivalirudin strategy was seen when GPI use was provisional in the bivalirudin arm but predominantly planned in the heparin arm. When GPI was used on a provisional basis in both anticoagulant regiments the reduction of bleeding still did not significantly favor bivalirudin. Furthermore, bivalirudin was associated with an increased risk of stent thrombosis and specifically acute stent thrombosis in STEMI patients. The use of the third-generation $\mathrm{P}_{2} \mathrm{Y}_{12}$ inhibitors in HEAT-PPCI and EUROMAX trials failed to limit this risk [34]. A second meta-analysis systematically evaluated the ischemic and bleeding efficacy of the various anticoagulant therapies recommended in STEMI in order to establish the optimal antithrombotic strategy. Bivalirudin was associated with a $48 \%$ and $32 \%$ decrease in major bleeding when compared to UFH plus GPI and heparin, respectively. On the other hand, bivalirudin resulted in a $65 \%$ increase in stent thrombosis, 39\% increase in MI, and a $44 \%$ increase in urgent revascularization, when compared with UFH with or without GPI [35]. Three recent meta-analyses, while confirming the increased incidence of acute stent thrombosis with bivalirudin, show no difference in the rate of MACE between bivalirudin and heparin with or without GPI [36-38]. However, a meta-analysis that compared the extended (up to $3 \mathrm{~h}$ ) high dose $(1.75 / \mathrm{kg} / \mathrm{h})$ of bivalirudin used in the BRIGHT trial and in a subgroup of patients in MATRIX and EUROMAX trials to heparin with or without GPI revealed no significant differences in acute stent thrombosis rates between the two antithrombotic options in STEMI patients. Furthermore this study, analyzing data from six large-scale randomized trials, confirmed that bivalirudin with or without prolonged infusion compared to conventional antithrombotic treatment in the STEMI setting resulted in significantly lower rates of major bleeding and all-cause mortality at 30 days [39]. In a rapidly evolving radial access world, another meta-analysis evaluated the interaction between bivalirudin and radial approach in ACS patients undergoing PCI. Bivalirudin's superiority regarding major bleeding is restricted only to patients with femoral access but not those undergoing PCI using the radial approach. On the other hand, the radial compared to femoral access resulted in significantly lower major bleeding rates only in patients treated with heparin, independently of the use of GPI. Thus, the combined use of radial approach and bivalirudin does not offer any additional benefit regarding bleeding as opposed to the use of either one alone [40].

The ESC guidelines for the STEMI management, based mainly on the results of the HORIZONS-AMI trial, recommend (class I recommendation and level of evidence B) therapy with bivalirudin and bailout use of GPI over UFH plus GPI, in all patients undergoing PCI independently of whether they are at high risk of bleeding or not [25]. However, taking into account the current European revascularization guidelines [16] and the results of recently published studies [31], we believe that heparin should be the preferred antithrombotic choice in this clinical setting. Bivalirudin results in higher rates of acute stent thrombosis [30, 31, 34] and should be considered as an alternative strategy only in patients at high risk of bleeding. Further investigation with more randomized trials is needed to investigate whether higher doses of bivalirudin with pronged infusion rates could prevent acute stent thrombosis.

The VALIDATE-SWEDEHEART trial, a multicenter randomized trial, will compare head-to-head bivalirudin and heparin alone in STEMI and NSTEMI patients pretreated with the new potent $\mathrm{P}_{2} \mathrm{Y}_{12}$ inhibitors and is expected to reveal the best antithrombotic approach in the era of new antiplatelet agents [41].

\section{CONCLUSION}

The introduction of bivalirudin in the management of patients undergoing PCI was welcomed by interventional cardiologists 
because, compared to heparin plus GPI, it was associated with better clinical outcomes, mainly driven by the lower rates of bleeding. However, data on the superiority of bivalirudin compared to heparin alone suggest that bivalirudin, an expensive direct thrombin inhibitor, does not offer any clinical advantage over heparin, a cheaper but effective anticoagulant agent, in the era of radial PCI and novel antiplatelet drugs.

\section{Impact on Daily Practice}

In line with current European guidelines for revascularization, our review doubts the superiority of bivalirudin over heparin in patients undergoing PCI and should be used only in patients at high risk of bleeding. UFH should be the first-choice anticoagulant during PPCI, as bivalirudin increases acute stent thrombosis rates.

\section{ACKNOWLEDGEMENTS}

No funding or sponsorship was received for this study or publication of this article.

All named authors meet the International Committee of Medical Journal Editors (ICMJE) criteria for authorship for this manuscript, take responsibility for the integrity of the work as a whole, and have given final approval for the version to be published.

\section{Disclosures. Constantinos}

Andreou, Christos Maniotis, and Michael Koutouzis have nothing to disclose.

Compliance with Ethics Guidelines. This article is based on previously conducted studies and does not involve any new studies of human or animal subjects performed by any of the authors.

Data Availability. Data sharing is not applicable to this article as no datasets were generated or analyzed during the current study.
Open Access. This article is distributed under the terms of the Creative Commons Attribution-NonCommercial 4.0 International License (http://creativecommons.org/licenses/ by-nc/4.0/), which permits any noncommercial use, distribution, and reproduction in any medium, provided you give appropriate credit to the original author(s) and the source, provide a link to the Creative Commons license, and indicate if changes were made.

\section{REFERENCES}

1. Libby P. Mechanisms of acute coronary syndromes and their implications for therapy. $\mathrm{N}$ Engl J Med. 2013;368(21):2004-13.

2. Stone GW, McLaurin BT, Cox DA, et al. Bivalirudin for patients with acute coronary syndromes. N Engl J Med. 2006;355(21):2203-16.

3. Stone GW, Witzenbichler B, Guagliumi G, et al. Bivalirudin during primary $\mathrm{PCI}$ in acute myocardial infarction. N Engl J Med. 2008;358(21):2218-30.

4. Warkentin TE, Greinacher A, Koster A. Bivalirudin. Thromb Haemost. 2008;99(5):830-9.

5. Di Nisio M, Middeldorp S, Buller HR. Direct thrombin inhibitors. $\mathrm{N}$ Engl J Med. 2005;353(10):1028-40.

6. Kastrati A, Mehilli J, Schuhlen H, et al. A clinical trial of abciximab in elective percutaneous coronary intervention after pretreatment with clopidogrel. N Engl J Med. 2004;350(3):232-8.

7. Bittl JA, Strony J, Brinker JA, et al. Treatment with bivalirudin (Hirulog) as compared with heparin during coronary angioplasty for unstable or postinfarction angina. Hirulog Angioplasty Study Investigators. N Engl J Med. 1995;333(12):764-9.

8. Lincoff AM, Kleiman NS, Kottke-Marchant K, et al. Bivalirudin with planned or provisional abciximab versus low-dose heparin and abciximab during percutaneous coronary revascularization: results of the Comparison of Abciximab Complications with Hirulog for Ischemic Events Trial (CACHET). Am Heart J. 2002;143(5):847-53.

9. Lincoff AM, Bittl JA, Kleiman NS, et al. Comparison of bivalirudin versus heparin during percutaneous coronary intervention (the Randomized Evaluation 
of PCI Linking Angiomax to Reduced Clinical Events [REPLACE]-1 trial). Am J Cardiol. 2004;93(9):1092-6.

10. Lincoff AM, Bittl JA, Harrington RA, et al. Bivalirudin and provisional glycoprotein IIb/IIIa blockade compared with heparin and planned glycoprotein IIb/IIIa blockade during percutaneous coronary intervention: REPLACE-2 randomized trial. JAMA. 2003;289(7):853-63.

11. Lincoff AM, Kleiman NS, Kereiakes DJ, et al. Long-term efficacy of bivalirudin and provisional glycoprotein IIb/IIIa blockade vs heparin and planned glycoprotein IIb/IIIa blockade during percutaneous coronary revascularization: REPLACE-2 randomized trial. JAMA. 2004;292(6):696-703.

12. Kastrati A, Neumann FJ, Mehilli J, et al. Bivalirudin versus unfractionated heparin during percutaneous coronary intervention. $\mathrm{N}$ Engl $\mathrm{J}$ Med. 2008;359(7):688-96.

13. Schulz S, Mehilli J, Ndrepepa G, et al. Bivalirudin vs. unfractionated heparin during percutaneous coronary interventions in patients with stable and unstable angina pectoris: 1-year results of the ISAR-REACT 3 trial. Eur Heart J. 2010;31(5):582-7.

14. Parodi G, Migliorini A, Valenti R, et al. Comparison of bivalirudin and unfractionated heparin plus protamine in patients with coronary heart disease undergoing percutaneous coronary intervention (from the Antithrombotic Regimens aNd Outcome [ARNO] trial). Am J Cardiol. 2010;105(8):1053-9.

15. Briguori C, Visconti G, Focaccio A, et al. Novel approaches for preventing or limiting events (Naples) III trial: randomized comparison of bivalirudin versus unfractionated heparin in patients at increased risk of bleeding undergoing transfemoral elective coronary stenting. JACC Cardiovasc Interv. 2015;8(3):414-23.

16. Kolh P, Windecker S, Alfonso F, et al. 2014 ESC/ EACTS Guidelines on myocardial revascularization: The Task Force on Myocardial Revascularization of the European Society of Cardiology (ESC) and the European Association for Cardio-Thoracic Surgery (EACTS). Developed with the special contribution of the European Association of Percutaneous Cardiovascular Interventions (EAPCI). Eur Heart J. 2014;35(37):2541-2619.

17. Gibson CM, Morrow DA, Murphy SA, et al. A randomized trial to evaluate the relative protection against post-percutaneous coronary intervention microvascular dysfunction, ischemia, and inflammation among antiplatelet and antithrombotic agents: the PROTECT-TIMI-30 trial. J Am Coll Cardiol. 2006;47(12):2364-73.
18. Roffi M, Patrono C, Collet JP, et al. 2015 ESC guidelines for the management of acute coronary syndromes in patients presenting without persistent ST-segment elevation: Task Force for the Management of Acute Coronary Syndromes in Patients Presenting without Persistent ST-Segment Elevation of the European Society of Cardiology (ESC). Eur Heart J. 2016;37(3):267-315.

19. Hamm CW, Bassand JP, Agewall S, et al. ESC guidelines for the management of acute coronary syndromes in patients presenting without persistent ST-segment elevation. The Task Force for the management of acute coronary syndromes (ACS) in patients presenting without persistent ST-segment elevation of the European Society of Cardiology (ESC). G Ital Cardiol (Rome). 2012;13(3):171-228.

20. Kastrati A, Neumann FJ, Schulz S, et al. Abciximab and heparin versus bivalirudin for non-ST-elevation myocardial infarction. $\mathrm{N}$ Engl $\mathrm{J}$ Med. 2011;365(21):1980-9.

21. Schulz S, Kastrati A, Ferenc M, et al. One-year outcomes with abciximab and unfractionated heparin versus bivalirudin during percutaneous coronary interventions in patients with non-ST-segment elevation myocardial infarction: updated results from the ISAR-REACT 4 trial. EuroIntervention. 2013;9(4):430-6.

22. Waksman $\mathrm{R}$, Bertrand $\mathrm{O}$, Driesman $\mathrm{M}$, et al. Bivalirudin versus unfractionated heparin during percutaneous coronary intervention in patients with non-ST-segment elevation acute coronary syndrome initially treated with fondaparinux: results from an international, multicenter, randomized pilot study (SWITCH III). J Interv Cardiol. 2013;26(2):107-13.

23. Hamon M, Rao SV, Steg G, et al. Bivalirudin versus unfractionated heparin in percutaneous coronary interventions of patients having received initial fondaparinux treatment: a propensity matched study. EuroIntervention. 2012;8(4):486-92.

24. Angeras O, Koul S, Albertsson P, et al. Heparin versus bivalirudin in patients with non ST-elevation acute coronary syndrome undergoing percutaneous coronary intervention-a report from SCAAR. Eur Heart J. 2013;34(Suppl 1):353.

25. Task Force on the management of ST-segment elevation acutemyocardial infarction of the European Society of Cardiology (ESC), Steg PG, James SK, et al. ESC guidelines for the management of acute myocardial infarction in patients presenting with ST-segment elevation. Eur Heart J. 2012;33(20):2569-619. 
26. Mehran R, Lansky AJ, Witzenbichler B, et al. Bivalirudin in patients undergoing primary angioplasty for acute myocardial infarction (HORIZONS-AMI): 1-year results of a randomised controlled trial. Lancet. 2009;374(9696):1149-59.

27. Stone GW, Clayton T, Deliargyris EN, Prats J, Mehran R, Pocock SJ. Reduction in cardiac mortality with bivalirudin in patients with and without major bleeding: the HORIZONS-AMI trial (Harmonizing Outcomes with Revascularization and Stents in Acute Myocardial Infarction). J Am Coll Cardiol. 2014;63(1):15-20.

28. Koutouzis M, Albertsson P. Bivalirudin during percutaneous coronary interventions in patients with ST segment elevation myocardial infarction. Acute Card Care. 2010;12(2):75-6.

29. Koutouzis M, Lagerqvist B, James S, et al. Unfractionated heparin administration in patients treated with bivalirudin during primary percutaneous coronary intervention is associated lower mortality and target lesion thrombosis: a report from the Swedish Coronary Angiography and Angioplasty Registry (SCAAR). Heart. 2011;97(18):1484-8.

30. Steg PG, van 't Hof A, Hamm CW, et al. Bivalirudin started during emergency transport for primary PCI. N Engl J Med. 2013;369(23):2207-17.

31. Shahzad A, Kemp I, Mars C, et al. Unfractionated heparin versus bivalirudin in primary percutaneous coronary intervention (HEAT-PPCI): an open-label, single centre, randomised controlled trial. Lancet. 2014;384(9957):1849-58.

32. Han Y. Bivalirudin versus heparin monotherapy and glycoprotein IIb/IIIa plus heparin for patients with AMI undergoing coronary stenting (BRIGHT). China Interventional Therapeutics (CIT 2014). Shanghai, China, March 21, 2014.

33. Leonardi S, Frigoli E, Rothenbuhler $M$, et al. Bivalirudin or unfractionated heparin in patients with acute coronary syndromes managed invasively with and without ST elevation (MATRIX): randomised controlled trial. BMJ. 2016;354:i4935.

34. Cavender MA, Sabatine MS. Bivalirudin versus heparin in patients planned for percutaneous coronary intervention: a meta-analysis of randomised controlled trials. Lancet. 2014;384(9943):599-606.

35. Bangalore S, Toklu B, Kotwal A, et al. Anticoagulant therapy during primary percutaneous coronary intervention for acute myocardial infarction: a meta-analysis of randomized trials in the era of stents and P2Y12 inhibitors. BMJ. 2014;349:g6419.

36. Capodanno D, De Caterina R. Bivalirudin for acute coronary syndromes: premises, promises and doubts. Thromb Haemost. 2015;113(4):698-707.

37. Navarese EP, Schulze V, Andreotti F, et al. Comprehensive meta-analysis of safety and efficacy of bivalirudin versus heparin with or without routine glycoprotein IIb/IIIa inhibitors in patients with acute coronary syndrome. JACC Cardiovasc Interv 8(1 Pt B):201-13.

38. Stone GW, Mehran R, Goldstein P, et al. Bivalirudin versus heparin with or without glycoprotein IIb/IIIa inhibitors in patients with STEMI undergoing primary percutaneous coronary intervention: pooled patient-level analysis from the HORIZONS-AMI and EUROMAX trials. J Am Coll Cardiol. 2015;65(1):27-38.

39. Fahrni G, Wolfrum M, De Maria GL, Banning AP, Benedetto U, Kharbanda RK. Prolonged high-dose bivalirudin infusion reduces major bleeding without increasing stent thrombosis in patients undergoing primary percutaneous coronary intervention: novel insights from an updated meta-analysis. J Am Heart Assoc. 2016;5(7):e003515.

40. Mina GS, Gobrial GF, Modi K, Dominic P. Combined use of bivalirudin and radial access in acute coronary syndromes is not superior to the use of either one separately: meta-analysis of randomized controlled trials. JACC Cardiovasc Interv. 2016;9(15):1523-31.

41. Erlinge D, Koul S, Eriksson P, et al. Bivalirudin versus heparin in non-ST and ST-segment elevation myocardial infarction-a registry-based randomized clinical trial in the SWEDEHEART registry (the VALIDATE-SWEDEHEART trial). Am Heart J. 2016;175:36-46. 